CIUDAD Y TERRITORIO

ESTUDIOS TERRITORIALES

ISSN(P): 1133-4762; ISSN(E): 2659-3254

Vol. LII, № 203, primavera 2020

Págs. 139-150

https://doi.org/10.37230/CyTET.2020.203.11

CC BY-NC 4.0

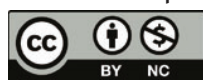

\title{
Más allá de la polémica: el Proyecto de Decreto de Habitabilidad y normas de diseño de viviendas y alojamientos dotacionales en la Comunidad Autónoma del País Vasco
}

Pablo GArCíA-Astrain

Director de Vivienda y Arquitectura Eusko Jaurlaritza - Gobierno Vasco

RESUMEN: El 15 de septiembre de 2019 se remitió el Proyecto de Decreto de habitabilidad y normas de diseño de viviendas y alojamientos dotacionales en la Comunidad Autónoma del País Vasco al Parlamento Vasco. El 17 de ese mismo mes se presentó públicamente este proyecto en el seno de un curso de verano de la Universidad del País Vasco en el Instituto de Arquitectura de Euskadi bajo el título Re_Vivienda Primer laboratorio de vivienda en Euskadi. El 19 de septiembre de 2019 el diario El Correo en su edición de Vizcaya abría su portada con el siguiente titular: "El Gobierno vasco quiere meter a los hombres en la cocina" a partir de ese momento se desató una inusitada polémica mediática a nivel de toda España con motivo de la inclusión de la perspectiva de género en la elaboración de dicha propuesta de norma. El presente artículo pretende dar cuenta del contenido del decreto poniendo el acento en esta cuestión de la perspectiva de género, recoger algunos de los elementos más destacados de la polémica e intentar establecer algunas conclusiones para orientar un debate que de alguna forma es ya ineludible en nuestras sociedades modernas sin olvidar por ello otros aspectos relevantes del texto normativo propuesto.

PALABRAS CLAVE: Controversia. Estándares de habitabilidad. Vivienda. Perspectiva de género.

Recibido: 07/11/2019; Revisado: 10/12/2019

Correo electrónico: p-garciaastrain@euskadi.eus 


\title{
Beyond the controversy: the Draft Decree of Habitability and rules for the design of housing in the Autonomous Community of the Basque Country
}

\begin{abstract}
On September 15, 2019, the draft Decree of habitability and design standards for housing and endowment accommodation in the Autonomous Community of the Basque Country was sent to the Basque Parliament. On the 17 th of the same month, this project was presented publicly in a summer course at the University of the Basque Country at the Basque Country Institute of Architecture under the title Re_Vivienda First housing laboratory in Euskadi. On September 19, 2019 the newspaper El Correo in its edition of Vizcaya opened its cover with the following headline: "The Basque Government wants to put men in the kitchen". From that moment, an unusual media controversy broke out at the level of all Spain on the occasion of the inclusion of the gender perspective in the elaboration of that proposal. This article intends to give an account of the content of the Decree, emphasizing the gender perspective issue, picking up some of the most prominent elements of the controversy and trying to establish some conclusions to guide a debate that is somehow unavoidable in our modern societies without forgetting other relevant aspects of the proposed normative text.
\end{abstract}

KEYWORDS: Controversy. Housing design standards. Housing. Gender perspective.

\section{El Proyecto de Decreto}

\subsection{Las intenciones y objetivos según la Exposición de Motivos}

os objetivos del proyecto de decreto son: desarrollar la Ley $3 / 2015$ de Vivienda de de 18 de Junio de 2015 , en particular en aquellas cuestiones relativas a la habitabilidad e inhabitabilidad de las viviendas, unificar la normativa de diseño dispersa en distintos decretos, actualizar la misma eliminando elementos que han generado disfunciones a lo largo del tiempo, potenciar la accesibilidad universal de las viviendas, establecer un marco de exenciones capaz de dar cabida y facilitar proyectos y promociones innovadores, fomentar la versatilidad de las viviendas e incorporar la perspectiva de género en el diseño de las viviendas. La exposición de motivos del decreto lo explica así:

"El derecho a disfrutar de una vivienda constituye una necesidad vital para el ser humano por cuanto condiciona el disfrute de otros derechos esenciales como tener un empleo, ejercer el derecho de sufragio, acceder a las prestaciones y a los servicios públicos, escolarizar a los hijos, gozar de la cultura y de un medio ambiente adecuado, compartir las vivencias con familiares y amigos y un sinfín más, reiteradamente puesto de relevancia tanto por la doctrina más autorizada como por los propios tribunales de justicia. El derecho a disfrutar de una vivienda y su realización efectiva facilitan y permiten al ser humano llevar una vida digna.

En 1948, la vivienda es mencionada por primera vez en la Declaración Universal de los Derechos
Humanos, cuando en su artículo 25.1 se contempla que toda persona tiene derecho a un nivel de vida adecuado que le asegure, así como a su familia, la salud y el bienestar, y en especial la alimentación, el vestido, la vivienda, la asistencia médica y los servicios sociales necesarios.

La Carta de los Derechos Fundamentales de la UE reconoce una serie de derechos personales, civiles, políticos, económicos y sociales de los ciudadanos y residentes de la UE, consagrándolos en el derecho comunitario. La Carta no contempla un derecho concreto a la vivienda, si bien existe un derecho importante a la ayuda en materia de vivienda, en concreto, el artículo 34.3 establece que con el fin de combatir la exclusión social y la pobreza, la Unión reconoce y respeta el derecho a una ayuda social y a una ayuda de vivienda para garantizar una existencia digna a todos aquellos que no dispongan de recursos suficientes, según las modalidades establecidas por el Derecho comunitario y las legislaciones y prácticas nacionales. La incorporación de esta Carta en el Tratado de Lisboa otorga rango de ley al "derecho a una ayuda social y a una ayuda de vivienda" en toda la Europa comunitaria.

La Constitución Española contempla en su artículo 47 que todos los españoles tienen derecho a disfrutar de una vivienda digna y adecuada y que los poderes públicos promoverán las condiciones necesarias y establecerán las normas pertinentes para hacer efectivo este derecho, regulando la utilización del suelo de acuerdo con el interés general para impedir la especulación. Añade que la comunidad participará en las plusvalías que genere la acción urbanística de los entes públicos.

En el ejercicio de la competencia exclusiva que el artículo 10.31 del Estatuto de Autonomía del País Vasco atribuye a la Comunidad Autónoma en mate- 
ria de vivienda, el Parlamento Vasco aprobó la Ley $3 / 2015$, de 18 de junio, de Vivienda, que tiene por objeto la regulación del derecho al disfrute de una vivienda digna y adecuada en el territorio de la Comunidad Autónoma del País Vasco.

La citada norma prevé que los poderes públicos promoverán las medidas oportunas para hacer efectivo el mencionado derecho, para que la vivienda reúna, entre otras cuestiones, las condiciones objetivas previstas al efecto en la legislación de ordenación de la edificación y normativa técnica aplicable, en lo que se refiere tanto a su funcionalidad como a su habitabilidad y a su seguridad y salubridad.

Asimismo, la Ley $3 / 2015$ de 18 de junio determina que es competencia de la Comunidad Autónoma del País Vasco la regulación de las condiciones mínimas de habitabilidad que serán de cumplimiento obligatorio para los instrumentos de planeamiento que aprueben otras administraciones públicas.

La norma señala que se considera infravivienda toda edificación o parte de ella, destinada a vivienda, que no cumpla con las mínimas condiciones de habitabilidad en los términos establecidos en la normativa de aplicación y, a tales efectos, prevé que el ayuntamiento pueda formular una declaración de inhabitabilidad cuando dichas condiciones no se cumplan.

En relación con esta cuestión, debe acudirse a la Ley 38/1999, de 5 de noviembre, de Ordenación de la Edificación, en cuanto que determina los requisitos básicos de la edificación que deben satisfacerse en el proyecto, la construcción, el mantenimiento, la conservación y el uso de los edificios y sus instalaciones, así como en las intervenciones que se realicen en los edificios existentes. Dichos requisitos se refieren a la funcionalidad (dimensiones de los espacios, dotación de las instalaciones, accesibilidad.), a la seguridad (seguridad estructural, seguridad en caso de incendio, seguridad de utilización), y a la habitabilidad (higiene, salud y protección del medio ambiente, protección contra el ruido, ahorro de energía y aislamiento térmico).

El Código Técnico de la Edificación, publicado en el Boletín Oficial del Estado el 28 de marzo de 2006, y sus posteriores modificaciones configuran el marco normativo que establece las exigencias básicas de calidad de los edificios de nueva construcción y de sus instalaciones, así como de las intervenciones que se realicen en los edificios existentes, de tal forma que permite el cumplimiento de los anteriores requisitos básicos. En concreto, determina los requisitos de seguridad estructural, seguridad en caso de incendio, seguridad de utilización y accesibilidad, ahorro de energía, protección contra el ruido y salubridad.

Por su parte, no existe en la Comunidad Autónoma del País Vasco una norma de ámbito autonómico que regule de forma exclusiva las condiciones mínimas de habitabilidad, aunque sí se han ido recogiendo algunas condiciones mínimas de las vivien- das y de los alojamientos dotacionales de forma sectorial como por ejemplo en la Ley 20/1997, de 4 de diciembre, para la Promoción de la Accesibilidad, el Decreto 317/2002, de 30 de diciembre, sobre actuaciones protegidas de rehabilitación del patrimonio urbanizado y edificado, el anexo IV del Decreto 39/2008, de 4 de marzo, sobre régimen jurídico de viviendas de protección pública y medidas financieras en materia de vivienda y suelo y la Orden de 12 de febrero de 2009, del Consejero de Vivienda y Asuntos Sociales, por la que se aprueban las Ordenanzas de Diseño de Viviendas de Protección Oficial.

Finalmente, en el ámbito municipal se han aprobado condiciones mínimas de habitabilidad en las Ordenanzas Municipales de Edificación de cada ayuntamiento.

Como consecuencia de lo anterior, resulta necesario unificar las condiciones mínimas de habitabilidad de las viviendas y de los alojamientos dotacionales para el conjunto del territorio de la Comunidad Autónoma del País Vasco, tanto en el caso de la obra nueva como en el caso de las viviendas existentes, al mismo tiempo que se procede a atender el mandato de desarrollo reglamentario previsto en la Ley 3/2015, de 18 de junio, de Vivienda.

La habitabilidad en cuanto que se configura como una condición de un espacio que permite desarrollar a las personas que lo ocupan un proyecto de vida, se encuentra vinculada a unos requisitos básicos de superficie y altura, confort térmico, equipamiento, salubridad, accesibilidad, uso y mantenimiento, sin olvidar la flexibilidad o versatilidad para adaptar la vivienda a las distintas etapas de la vida así como a los nuevas necesidades y formas de vida modernas.

Por lo tanto, con esta nueva normativa se posibilita la creación de espacios más versátiles, y flexibles que se adaptan a las circunstancias de cada unidad convivencial en el paso del tiempo, de forma que la distribución de la vivienda permita la diferente compartimentación de la misma.

Además, resulta indispensable en la sociedad en la que vivimos, que la habitabilidad contemple también cuestiones relacionadas con la accesibilidad universal y la perspectiva de género.

Por último, bajo determinadas circunstancias, se posibilita que los nuevos proyectos que se desarrollen para la implantación de edificios de uso residencial o aquellos de rehabilitación que se lleven a cabo, una vez entre en vigor esta norma, conviertan la habitabilidad en uno de los elementos clave que fomentará la innovación y la calidad arquitectónica en el sector de la construcción y de la edificación residencial.

Esta norma establece las condiciones de emplazamiento de forma que la vivienda resultante sea digna y en armonía con el entorno y el medio ambiente, permita su utilización, mantenimiento y disfrute en unas condiciones económicas proporcionadas. 
Por tanto, esta norma es necesaria y proporcional puesto que no existen otras medidas menos restrictivas de derechos o que impongan menos obligaciones a las personas destinatarias para garantizar un marco normativo estable, predecible, integrado, claro y de certidumbre, que facilite su conocimiento y comprensión y, en consecuencia la toma de decisiones de las personas titulares de las viviendas, de las Administraciones Públicas y de las empresas del sector.

El decreto consta de una parte expositiva, dieciocho artículos, dos disposiciones adicionales, cuatro disposiciones transitorias, una disposición derogatoria, dos disposiciones finales y siete anexos.

El capítulo I establece, bajo la rúbrica de disposiciones generales, el objeto del presente decreto que no es otro que fijar las condiciones mínimas de habitabilidad y las normas de diseño que deben cumplir las viviendas y alojamientos dotacionales ubicados en el territorio de la Comunidad Autónoma del País Vasco, extremo que debe tenerse en cuenta desde el momento en el que se procede a la aprobación del planeamiento que recoge esa previsión de viviendas.

Asimismo, es objeto de la norma determinar las normas que deben respetar las viviendas de protección pública a efectos de su calificación.

El capítulo II regula las condiciones de habitabilidad y las normas de diseño que deben cumplir las viviendas en general, con independencia de que se trate de viviendas de protección pública o de promoción privada, puesto que el denominador común es garantizar a las personas usuarias de las viviendas ubicadas en esta Comunidad Autónoma unas condiciones dignas para el correcto desarrollo de su proyecto de vida.

La norma establece también como parte de las condiciones de habitabilidad de una vivienda, medidas o condiciones que deben adoptarse en los edificios que albergan esas viviendas puesto que es un elemento que no se puede disociar de aquéllas, en cuanto que no puede considerarse habitable una vivienda ubicada en un edificio que no atiende a unas condiciones mínimas de seguridad estructural, salubridad y accesibilidad.

La norma diferencia entre condiciones de habitabilidad y normas de diseño en función de si se trata de viviendas existentes, viviendas sometidas a alguna actuación de rehabilitación o viviendas de nueva construcción.

En este sentido, consciente de que el parque de viviendas de la Comunidad Autónoma del País Vasco se caracteriza por su antigüedad y los problemas asociados, como la falta de accesibilidad o de eficiencia energética, extremo que dificulta que las mismas puedan adecuarse a los requisitos de la normativa actual, determina unas condiciones mínimas de habitabilidad para las viviendas existentes a la entrada en vigor de la norma.
Por el contrario, para las actuaciones de rehabilitación adopta un criterio que se fundamenta en el alcance de la actuación para dirigir a la persona que promueve la actuación, bien al cumplimiento, al menos, de las condiciones mínimas de habitabilidad contempladas para las viviendas existentes bien al cumplimiento de las normas de diseño que se establecen para las viviendas de nueva construcción.

En todo caso, conociendo la situación del parque actual de viviendas antes señalado y los esfuerzos que se vienen realizando en relación con el fomento de la sostenibilidad y la innovación en el sector de la construcción, la norma habilita un instrumento para que en determinados casos pueda acordarse la exención de alguno de los requisitos que en relación con la habitabilidad se establecen en la misma.

El capítulo III regula la declaración de inhabitabilidad como el instrumento del que dispone el Ayuntamiento, entidad competente señalada a tal efecto por la Ley $3 / 2015$, de 18 de junio de Vivienda, para poder intervenir en los casos en los que una vivienda o un alojamiento dotacional no cumpla las condiciones mínimas de habitabilidad que le resulten de aplicación. Así, se desarrollan las previsiones de la norma con rango legal, señalando el contenido de la declaración de inhabitabilidad, así como las consecuencias de la adopción o no de las medidas a adoptar contempladas en la misma.

Finalmente, el capítulo IV señala que corresponde al ayuntamiento de conformidad con lo previsto en la legislación urbanística, fiscalizar el cumplimiento de las condiciones de habitabilidad, aunque subsidiariamente dicha responsabilidad puede recaer en el órgano competente en materia de vivienda del Gobierno Vasco.

Asimismo, considerando que en la Ley 3/2015, de 18 de junio, de vivienda se contemplan, entre otras, infracciones referidas a la infravivienda, el uso inadecuado de la vivienda y las condiciones de habitabilidad, la norma señala que el incumplimiento de lo establecido en esta norma dará lugar a la aplicación del régimen sancionador previsto en la citada ley.

Por último, se debe señalar que la formulación y tramitación de este Decreto se ha sujetado a lo señalado en los artículos 19 a 21 de la Ley 4/2005, de 18 de febrero, para la Igualdad de Mujeres y Hombres, así como a las directrices para la realización de la evaluación previa del impacto en función del género y la incorporación de medidas para eliminar desigualdades y promover la igualdad de mujeres y hombres aprobadas por Acuerdo del Consejo de Gobierno de 21 de agosto de 2012. (... $)^{1 "}$.

Además de la estructura del decreto mencionada en la exposición de motivos que se organiza por capítulos en su parte articulada, el cuerpo normativo técnico por así decirlo del texto reside en sus 
siete anexos, la parte relativa a la definición de la vivienda se encuentra mayormente en el Anexo III. Remitiéndose los demás anexos de una forma $u$ otra a éste. Es por tanto en el anexo tercero donde se encuentra el núcleo de la propuesta, y en particular de la propuesta de incorporación de la perspectiva de género en la vivienda que se centra fundamentalmente en los siguientes aspectos:

- Medidas y criterios para reforzar la seguridad y la percepción de seguridad en las zonas comunes del edificio. Exigiendo entre otros aspectos, unos mínimos de trasparencia entre las puertas de compartimentación incluidas las de los ascensores.

- Volver a poner el hogar en el centro de la vivienda, entendiendo el hogar como el espacio para cocinar, y el conjunto de tareas asociadas hasta ahora a la cocina.

- Des-jerarquización de los dormitorios reconvertidos ahora en habitaciones multiuso aumentando su tamaño mínimo.

- Ampliación de los estándares de espacios para almacenaje de la vivienda.

\subsection{Contenidos}

En el Anexo III se recogen las Normas de Diseño para las viviendas de nueva construcción, que se dividen en Normas para los Edificios (Apartado III-A: El edificio) y Normas para la vivienda, propiamente dicha (Apartado III-B. La vivienda).

\subsubsection{Contenidos para los edificios}

Entre las Normas para los Edificios, destacamos:

Normas sobre Condiciones de seguridad. (Apartado III-A.1):

"Todos los espacios y elementos comunes, incluidas las escaleras, en todas las plantas del edificio, serán proyectados y ejecutados con una configuración espacial adecuada en orden a garantizar la percepción de seguridad.

Los accesos al interior del edificio se situarán a menos de 2 metros de profundidad con respecto a la fachada y evitarán la generación de recovecos.

${ }^{1}$ Exposición de Motivos del Proyecto de Decreto sobre condiciones de habitabilidad y normas de diseño de las viviendas y alojamientos dotacionales de la CAPV.

https://www.legegunea.euskadi.eus/documentacion-relevan-
Los portales de acceso presentarán una configuración espacial clara y regular.

Se evitará en todos los espacios comunes la existencia de ángulos muertos, retranqueos, esquinas, zonas oscuras y demás espacios que puedan poner en peligro la seguridad de las personas usuarias del edificio. En caso de que existan este tipo de ángulos o esquinas, se deberá disponer de espejos u otros sistemas visuales para que se visibilice.

Todos los espacios comunes deberán disponer de una iluminación adecuada y deberán contar con encendido automático.

Cuando los huecos de iluminación o ventilación de la fachada de un edificio estén situados a una altura exterior menor de $2 \mathrm{~m}$, dispondrán de sistemas de seguridad contra el intrusismo.

Los ascensores dispondrán de llavines de acceso desde y hasta el garaje, para evitar problemas de intrusión. (...)".

Normas sobre Condiciones de acceso y de accesibilidad (Apartado III-A.3).

\section{“[...]}

Espacios comunes de circulación. Los elementos de comunicación entre las distintas plantas (escaleras y ascensor) permitirán el acceso directo a la totalidad de viviendas y sus anejos (trasteros y garajes) y a los locales o cuartos comunes de la edificación.

Los itinerarios de comunicación -pasillos, distribuidores y corredores- deben ser, hasta la vivienda o anejo, accesibles y seguros, sin recovecos o con medidas que garanticen la seguridad.

La anchura y disposición de los pasos de circulación en el interior del edificio permitirán el paso horizontal de un prisma de doscientos centímetros de largo, por setenta centímetros de ancho por setenta centímetros de alto $(200 \times 70 \times 70 \mathrm{~cm})$.

La altura libre de las zonas comunes de circulación será como mínimo de 2,40 m que podrán reducirse en $20 \mathrm{~cm}$ en los pasos críticos.

[...].

Ascensor. Se asegurará que el edificio facilita el acceso a su interior y la comunicación con sus elementos comunes (garajes, trasteros y otras dependencias anejas de uso comunitario), en todas

cia-juridica/proyecto-de-decreto-que-regula-las-condicionesminimas-de-habitabilidad-y-las-normas-de-diseno-de-las-vi viendas-y-alojamientos-dotacionales-en-la-comunidad-auto noma-del-pais-vasco/x59-contfich/es/ 
sus plantas, de forma independiente y segura para todas las personas.

La dotación de ascensores será tal que dé adecuado servicio a todas las viviendas y, por tanto, su número irá en función del tráfico de personas previsto.

La dotación de ascensores dispondrá de puertas de rellano y de cabina con una superficie trasparente del $30 \%$ situada entre 0,7 y $1,7 \mathrm{~m}$ de altura."

\subsubsection{Contenidos para las viviendas}

Dentro de las Normas para las viviendas (Apartado III-B. La vivienda), destacamos:

Normas sobre los Espacios de la vivienda (Apartado III-B.5: Condiciones espaciales, punto 3- Elementos de programa: Espacios de la vivienda).

\begin{abstract}
“(...)
Espacios de habitación (Habitaciones): La vivienda debe tener uno o más espacios de habitación que sean multifuncionales y en cualquier caso aptos para el descanso y para dormir. Las habitaciones tendrán una superficie mínima de $10 \mathrm{~m}^{2}$, y de $11,5 \mathrm{~m}^{2}$ si incluyen un espacio para almacenaje en su interior.
\end{abstract}

\section{(...)}

Espacios para almacenamiento: La vivienda deberá disponer de los siguientes espacios de almacenamiento a razón de $2 \mathrm{~m}^{3}$ mínimo por persona y considerando dos personas por habitación:

- Espacio para almacenamiento personal en las habitaciones: 1,55 $\mathrm{m}$ de largo $\times 0,60 \mathrm{~m}$ de fondo $\mathrm{x}$ 2,20 m de alto por habitación.

- Espacio para almacenamiento general: $\mathrm{H} \times 1,55$ $\mathrm{m}$ de largo $\times 0,60 \mathrm{~m}$ de fondo $\times 2,20 \mathrm{~m}$ de alto $\mathrm{y}$ donde $\mathrm{H}$ es el número de habitaciones.

Los espacios para almacenamiento personal podrán formar parte de la superficie mínima útil de las habitaciones o encontrarse de forma adjunta a la habitación con acceso directo. Los espacios de almacenamiento general podrán estar ubicados en los espacios de circulación o añadirse a otros espacios.

(...)".

Normas sobre las relaciones entre espacios de la vivienda (Apartado III-B.5: Condiciones espaciales, punto 5- Relación entre los espacios).

\section{"Relación entre los espacios:}

Los recorridos de circulación y circunferencias de giro se podrán superponer con los espacios mínimos siempre que no se menoscabe el uso o los usos básicos contemplados en cada estancia.

Las habitaciones, cocinas y aseos no podrán servir de paso obligado a otras estancias.

En viviendas de una sola habitación, el acceso al aseo se podrá efectuar a través de pasillo, vestíbulo, distribuidor o de la misma habitación. En todo caso, entre el inodoro y los recintos de cocina, comedor o estar será preciso atravesar dos puertas interiores de vivienda.

Cuando en la vivienda exista más de una habitación, estas estarán compartimentadas. En estos casos el aseo completo será accesible desde espacios de circulación de la vivienda (vestíbulo, pasillo o distribuidor) y en él se podrá inscribir un cilindro de $120 \mathrm{~cm}$ de diámetro y $70 \mathrm{~cm}$ de altura sin más reformas que la eliminación del bidé.

El espacio para cocinar tendrá preferentemente las dimensiones de cocina comedor. En su defecto, el espacio se diseñará colindante con el estar comedor de forma que pueda unirse a éste de forma directa, y/o tener una conexión visual directa. Este espacio deberá tener en cuenta las condiciones de accesibilidad practicable de este decreto". ${ }^{2}$

\subsubsection{Contenidos sobre accesibilidad}

La accesibilidad de las viviendas ha sido otro de los aspectos claves del decreto, que, aunque haya pasado inadvertido para los medios de comunicación generalistas, entraña modificaciones no menos profundas que las generadas por la inclusión de la perspectiva de género.

Se trataba aquí de dar un paso más con respecto a las exigencias establecidas por la ley de promoción de la accesibilidad en la CAPV de 1997 y su posterior decreto de desarrollo en el cual se establece las exigencias para el espacio urbano, los edificios públicos y equipamientos, así como para los edificios de uso residencial. Con aquel de decreto se garantiza la accesibilidad hasta todas las viviendas y una dotación de viviendas adaptadas a personas en situación de discapacidad a razón de una vivienda adaptada por cada cincuenta viviendas o fracción para las promociones de vivienda libre, y una por cada veinticinco o fracción para las promociones de vivienda protegida. 
Con el decreto de habitabilidad y normas de diseño propuesto, lo que se pretende es que, respetando esta reserva, el resto de las viviendas, esto es la totalidad de las viviendas, cumplan unos mínimos que permitan usar la vivienda por una persona en situación de discapacidad o con movilidad reducida.

Para ello se exige que al menos una habitación, las estancias vivideras y un aseo completo cumplan las exigencias de accesibilidad y practicabilidad del decreto $68 / 2000$. Se trata de responder a situaciones e discapacidad sobrevenida y de pensar la vivienda en una sociedad que tiende al envejecimiento de forma acelerada. El decreto lo explicita de la siguiente manera:

Condiciones de acceso y accesibilidad. (Apartado III.B.4)

"Con independencia de las reservas en los edificios destinados a viviendas contempladas en la Ley 20/1997, de 4 de diciembre, para la Promoción de la Accesibilidad, todas las viviendas, incluidas las viviendas unifamiliares, bifamiliares y adosadas, tienen que introducir, como mínimo, medidas destinadas a alcanzar un nivel de accesibilidad practicable $y$, a tales efectos, tienen que cumplir las siguientes condiciones:

1. Tanto si la vivienda se desarrolla en un único nivel como si lo hace en diferentes niveles, deberá tener los siguientes espacios practicables: el acceso, un aseo completo, la cocina, el estar-comedor y una habitación.

En los espacios practicables se tiene que poder inscribir una circunferencia de un metro y veinte centímetros de diámetro $(\varnothing 1,20 \mathrm{~m})$, libre de equipamientos fijos de hasta $0,70 \mathrm{~m}$ de altura. Los recorridos interiores de estos espacios deben tener una anchura mínima de paso de 0,80 m.

Cuando un aseo completo disponga de una ducha enrasada con el suelo, su superficie computará a efectos de permitir el círculo de maniobra de 1,20 m. Asimismo, en caso de que el aseo disponga de un bidé computará a estos efectos la superficie resultante de la reforma para su eliminación.

Cuando los espacios practicables se desarrollen en diferentes plantas, la vivienda dispondrá de un espacio de comunicación vertical libre de obstáculos capaz de albergar una plataforma elevadora de traslación vertical según las características establecidas en el Decreto 68/2000.

2. La puerta de acceso a la vivienda debe tener una anchura mínima de paso de $0,90 \mathrm{~m}$ y una altura libre mínima de $2 \mathrm{~m}$. Las puertas de acceso a los espacios internos de la vivienda, deben tener una anchura libre mínima de paso de 0,80m y una altura libre mínima de $2 \mathrm{~m}$.

Los espacios interiores destinados a la circulación que conecten el acceso a la vivienda y los espacios practicables deben tener una anchura mínima de 0,95 $\mathrm{m}$ y permitir la inscripción de un círculo de 1,20 m delante de las puertas de acceso a los espacios practicables y de $0,95 \mathrm{~m}$ para el resto de espacios destinados a la circulación que den acceso a los espacios no practicables de la vivienda. Se admite que el círculo de $1,20 \mathrm{~m}$ se inscriba con las puertas abiertas.

3. La anchura libre mínima de las escaleras interiores de una misma vivienda será de 0,80 m".

\subsubsection{Otros aspectos desarrollados}

Por último, el Decreto también incluye otros aspectos como la necesidad de garantizar un soleamiento mínimo a la vivienda, la versatilidad de la vivienda, la posibilidad de acogerse a exenciones del cumplimiento de la propia norma en determinados casos de rehabilitación o de programas de innovación, así como una primera aproximación a la regulación de las viviendas colaborativas.

"CAPÍTULO I. DISPOSICIONES GENERALES (...)

Artículo 6.- Coordinación con el planeamiento urbanístico, las ordenanzas edificatorias municipales y las licencias urbanísticas.

1. Las condiciones mínimas de habitabilidad contempladas en el presente Decreto son de cumplimiento obligatorio para los instrumentos de planeamiento que aprueben otras administraciones públicas.

Las ordenanzas edificatorias municipales tienen que respetar las determinaciones de este Decreto.

2. Aquellos instrumentos de planeamiento urbanístico que incluyan entre sus determinaciones la ordenación pormenorizada de ámbitos, áreas o parcelas con edificaciones de uso residencial vivienda, incluirán en su memoria la justificación de que su diseño posibilita el soleamiento en, al menos, una habitación de las áreas de convivencia o privacidad. Asimismo, esta exigencia se incluirá en la normativa de urbanización y edificación de los citados instrumentos de planeamiento urbanístico. (...)".

"ANEXO III. NORMAS DE DISEÑO DE VIVIENDAS DE NUEVA CONSTRUCCION. (...)

6- Versatilidad: La compartimentación, si la hay, de la vivienda será preferentemente concebida con 
criterios de vivienda versátil que permitan la evolución y transformación de la misma a lo largo del tiempo siempre que se mantengan inalterables, conforme al proyecto técnico original, la dotación obligatoria de carácter fijo consistente en el equipo de cocina y los aseos, los elementos que tengan una función estructural o sean elementos comunes al edificio y los que conformen el cierre con el exterior. (...)"

"ANEXO VI. SUPUESTOS DE EXENCIÓN DEL CUMPLIMIENTO DE LAS CONDICIONES DE HABITABILIDAD.

\section{1.- Supuestos de exención}

Se podrá eximir del cumplimiento de las condiciones de habitabilidad y normas de diseño que se establecen en la presente norma en los siguientes supuestos:

a) Edificios de vivienda o viviendas existentes cuya particular configuración no permita el cumplimiento exhaustivo de las condiciones de habitabilidad, pero cuyo diseño específico albergue valores de habitabilidad alternativos, dignos de toma en consideración, y debidamente justificados.

b) Proyectos que tengan por objeto intervenciones en un edificio de vivienda existente objeto de rehabilitación aislada con destino a vivienda o alojamiento dotacional cuya particular configuración no permita el cumplimiento exhaustivo de las condiciones de habitabilidad, pero cuyo diseño especifico albergue valores de habitabilidad alternativos dignos de toma en consideración, y debidamente justificados.

c) Proyectos que tengan por objeto intervenciones en uno o varios edificios de vivienda existentes objeto de rehabilitación con destino a vivienda o alojamiento dotacional cuya particular configuración no permita el cumplimiento exhaustivo de las condiciones de habitabilidad, pero cuyo diseño específico albergue valores de habitabilidad alternativos dignos de toma en consideración, y debidamente justificados.

Se presume que concurre esta circunstancia en el caso de intervenciones de edificación en solares, o de rehabilitación integral de edificios en ámbitos urbanos y áreas consolidadas en las que la especial y compleja morfología de las edificaciones y del parcelario existente imposibilite el cumplimiento de las condiciones de habitabilidad y normas de diseño contempladas en esta norma.

d) Proyectos de edificios de nueva planta desti- nados a uso residencial que tengan un carácter innovador.

Un proyecto puede ser de carácter innovador tanto desde el punto de vista tipológico como constructivo. Se considera que un proyecto es innovador cuando se trata, entre otros, de edificios que tienen la consideración de experimentales por las prestaciones del edificio o por otras circunstancias (Viviendas colaborativas o "co-housing", nuevas tecnologías), o de viviendas experimentales con alto grado de creatividad.

e) En el caso de proyectos en los que convergen varios de los supuestos contemplados en los apartados anteriores".

\section{"ANEXO VII. DEFINICIONES (...)}

Vivienda colaborativa: Es aquella vivienda de titularidad pública o privada que cumpliendo con el programa mínimo de vivienda o de alojamiento dotacional se encuentra inserta en un edificio destinado a ser ocupado o habitado por un grupo de personas que, sin constituir núcleo familiar, compartan servicios y se sometan a un régimen común y dispongan obligatoriamente de instalaciones, servicios y zonas comunes asimilables como mínimo a los de los alojamientos dotacionales. (...)

Vivienda versátil: Vivienda concebida de forma que facilite, de forma fácil y rápida, su adecuación a diversas funciones y a las necesidades cambiantes de sus ocupantes, y que quede abierta a la intervención de las personas usuarias en su compartimentación con un mínimo de obra seca". ${ }^{2}$

\section{Las reacciones}

El repentino ruido mediático en prensa escrita, radio y televisión, así como redes sociales en torno a este decreto se centró esencialmente en torno a la cuestión de la inclusión de la perspectiva de género y de las medidas que la norma incluye en este sentido. Titulares como: El Gobierno vasco quiere que los hombres entre en la cocina (El Correo ed. Bizkaia 19/09/2019), Pisos "más versátiles flexibles eficientes y accesibles" (El Correo ed. Bizkaia 19/09/2019), El Gobierno Vasco obliga a agrandar las cocinas para "combatir el machismo" (La Vanguardia - 20/09/2019). ¿Cuántos deben caber en la cocina? (El Correo ed. Bizkaia 20/09/2019), Del fogón de la amama a la cocina de la iguadad. (El Correo ed. Bizkaia 20/09/2019), Totalitarismo de género (La Razón - 20/09/2019),

\footnotetext{
2 idem.
} 
El tamaño sí importa (La Razón - 20/09/2019), El Gobierno Vasco lleva a la cocina la lucha contra la brecha de género (Expansión - 20/09/2019), Cocinas con espacio suficiente para hombre y mujer (El País - 20/09/2019), Hasta la cocina (El Correo ed. Bizkaia - 20/09/2019), De puertas para adentro (El Correo Alava - 20/09/2019, El gobierno vasco impondrá cocinas más grandes contra el machismo (ABC - 21/09/2019), Cocretismo (El Correo ed. Bizkaia -21/09/2019), Meterse hasta la cocina en la intimidad (ABC - 23/09/2019) o Viviendas ideológicas (La Razón - 24/09/2019), dan cuenta del inusitado impacto mediático que tuvo el decreto por el mero hecho de abordar el tema. Sin ánimo de reproducir opiniones ajenas, algunas de ellas execrables, recogemos aquí dos editoriales que, aunque plagados de inexactitudes, como editoriales, aunque pausados aportan la medida de la virulencia del debate suscitado.

\subsection{Hasta la cocina: El Editorial de El Correo}

"La igualdad de género no se combate con cambios en la distribución de los hogares, sino con un reparto equilibrado de tareas y nuevos hábitos sociales La lucha por una igualdad de género real es una carrera de fondo en la que difícilmente será posible alcanzar la meta sin una profunda concienciación social previa, que ha de traducirse en cambios en la vida cotidiana al margen de las reformas legales que allanen el camino. La tenaz persistencia de hábitos enraizados desde una época en la que las mujeres, por su mera condición, estaban predestinadas a asumir en exclusiva el cuidado del hogar y su presencia en el mercado laboral era testimonial está detrás de la brecha salarial o el desplome de la natalidad, entre otros problemas que es preciso corregir. Mientras las tareas domésticas y la atención tanto de los hijos como de los mayores sean una labor preponderadamente femenina resultará muy difícil avanzar en ese terreno. El Gobierno vasco acaba de presentar el borrador de una normativa sobre la construcción de nuevas viviendas que, entre otras medidas, aumenta de cinco a siete metros cuadrados el espacio mínimo que deberá destinarse a las cocinas. De esa forma aspira a promover que las parejas compartan tareas. La igualdad de género tiene múltiples frentes de actuación. Queda tanto por hacer para acercarse a ella que sería irresponsable desdeñar ninguno. Pero resulta tan bienintencionado como ingenuo pretender que el tamaño de las cocinas va a resolver un desafío de semejante complejidad. Incluso que puede ayudar de forma apreciable en la consecución de ese objetivo. Porque no estamos ante una cuestión en la que sea primordial el reparto de espacios, sino una equilibrada distribución de tareas en el hogar.
Un ámbito protegido por la intimidad en el que el Ejecutivo dispone de una mínima capacidad de maniobra, más allá de favorecer una sensibilización que destierre añejos estereotipos machistas y una educación en los valores de la igualdad entre las nuevas generaciones que será más efectiva cuanto más vean éstas que sus propias familias practican con el ejemplo. Las nuevas viviendas han de ser edificadas de acuerdo a las cambiantes necesidades sociales. Resulta indiscutible, por ejemplo, la conveniencia de adaptar su estructura a la movilidad de personas mayores impedidas cuando nos azota el envejecimiento de la población. Pero aspirar a modificar hábitos muy enraizados con meras fórmulas arquitectónicas es ir demasiado lejos". (Editorial Diario El Correo. Edición Bizkaia 20/09/2019)

\subsection{Meterse hasta la cocina en la intimidad: El Editorial de $A B C$}

"El Gobierno vasco se ha puesto a la tarea de legislar las condiciones que a partir de ahora deben cumplir las viviendas. Además de las lógicas características técnicas de habitabilidad ha incluido en la normativa la perspectiva de género y hasta tal punto es así que inscribe la ley en la lucha contra el machismo. Para ello no se le ha ocurrido mejor cosa que, por ejemplo, ordenar que las cocinas sean más amplias. A partir de ahora en el País Vasco deberán tener al menos siete metros cuadrados, en lugar de los cinco actuales. No parece probable que en esos dos metros de más resida la liberación de la mujer o la igualdad entre sexos (género tienen las palabras), ni que vaya a terminarse con el «machismo» que el Ejecutivo de Urkullu cree que anida en los hombres vascos. Ya puestos a la tarea de organizar la casa a los ciudadanos, el PNV también quiere luchar contra la «jerarquización» del tamaño de los dormitorios, proponiendo que el destinado a los hijos sea mayor que ahora, pues advierte el avispado legislador que los hijos se van cada vez más tarde de la casa y, según van creciendo, merecen más espacio. Es decir, en vez de legislar para crear condiciones para que los jóvenes se independicen antes, el Gobierno de Urkullu lo que hace es ampliarles su habitación. Valga este proyecto normativo para volver a alertar cómo, a golpe de leyes cuyo combustible es lo "políticamente correcto», se va limando la libertad del individuo para organizarse la vida como mejor le convenga. El hogar era uno de los pocos espacios donde aún reinaba el libre albedrío de la persona, acosada en cuanto sale a la calle por un diluvio de normas que prohíben o autorizan casi todo. Estaba por ver que una administración invadiese el área más personal, el sanctasantórum de la intimidad... Pues en el País Vasco ese hipertrofiado normativismo ya ha entrado «hasta la cocina». (Editorial Diario ABC 23/09/ 2019) 
Más allá del foco mediático centrado exclusivamente en un único aspecto novedoso de la propuesta normativa, hay que mencionar que el objetivo de ésta no es la inclusión de la perspectiva de género en sí mismo, sino dotar a la vivienda de un marco normativo global que permita su evolución, teniendo especial cuidado de no eliminar ninguno de los muchos avances en vivienda procurados por las normativas actuales que le preceden, pero eliminando rigideces excesivas, permitiendo y exigiendo cuando procede la incorporación de criterios que suponen una actualización del fin último de la vivienda, como es por ejemplo procurar dignidad a sus moradores en todas las etapas de la vida.

De esta forma, dentro de una visión integral de lo que debe ser una vivienda en el siglo XXI, la definición del concepto de vivienda que toda norma encierra se ha elaborado con una vocación integral e integradora incluyendo, la versatilidad de la vivienda, la accesibilidad universal de la misma, su carácter potencialmente innovador, su propia evolución posible a lo largo del tiempo, su eficiencia energética y sostenibilidad, efectivamente la perspectiva de género, y finalmente su encaje y articulación con la normativa técnica de rango superior.

Conviene decir que lo que se busca no es legislar más, sino legislar diferente y sobre todo, mejor. En este sentido no se añaden más filtros o controles, simplemente se deberán tener en cuenta y justificar los preceptos de esta norma como hasta la fecha se ha venido haciendo con, por ejemplo, la Ordenanza de Diseño de Viviendas de Protección Oficial de la Comunidad Autónoma del País Vasco. Así mismo lo que se persigue con esta norma es fundamentalmente posibilitar la aparición de nuevos tipos de vivienda que actualmente se ven impedidos por la normativa y que son reclamados por distintos sectores, en efecto como explica al menos uno de los titulares de prensa: viviendas más versátiles flexibles eficientes y accesibles, pero también más colaborativas y compartidas si es el caso, y sí: incluyendo la perspectiva de género desde su diseño inicial.

Decía el Catedrático Xavier MonTEYs, en su ensayo La Habitación que:

"Se espera en materia de vivienda se produzca algún gesto significativo en España más allá de discurso técnico, demasiado apoyado en los nuevos sistemas constructivos y en los criterios de sostenibilidad, y que coloca el futuro de la casa más bajo la tutela de los ingenieros que de los arquitectos."

y reclamaba un:

\begin{abstract}
"gesto tan significativo en el campo de la vivienda como lo que en el campo de la familia ha representado el reconocimiento de los derechos de las parejas de hecho, de las familias monoparentales o de las parejas homosexuales". (MonteYs, 2014)
\end{abstract}

Sin entrar a terciar en la eterna pugna entre ingenieros y arquitectos, y sin pretender que el proyecto de decreto sea ese gran gesto tan esperado, a tenor de la polémica suscitada, y del hecho como apuntó el Consejero Iñaki Arriola en el Parlamento Vasco el pasado día 25 de octubre de que el proyecto de decreto ha conseguido "que se hable como nunca antes sobre cómo de ser una vivienda"; podemos afirmar que se trata de alguna forma de una contribución en esa dirección reclamada por Monteys.

En efecto, es nuestra responsabilidad como Gobierno no solo garantizar el acceso a una vivienda digna - un derecho consagrado en Euskadi como Derecho Subjetivo desde la aprobación de La Ley de Vivienda de 2015- sino también promover el crecimiento sostenible de un parque público de alquiler con el que poder responder a la demanda creciente de vivienda, y hacerlo de forma acorde a la evolución de la sociedad y los nuevos tipos de unidad convivencial que se dan en ella, así como con las nuevas exigencias de todo tipo que recaen sobre la vivienda tanto pública como privada.

Conviene apostillar a su vez que los primeros estudios y análisis de contraste de la norma efectuados sobre promociones concretas y reales de la Viceconsejeria de Vivienda del Gobierno Vasco muestran que se puede aplicar los nuevos estándares de diseño que incluyen la perspectiva de género sin pérdida de edificabilidad ni número de viviendas alguna y respetando las volumetrías inicialmente previstas. Eso sí, cambiando la distribución y configuración interna de las viviendas. Por lo que a priori, no existe repercusión económica derivada de la aplicación de dichos estándares de superficie en particular salvo que se quiera mantener exactamente el mismo programa tipo de vivienda jerarquizada que en la actualidad.

\section{Conclusiones}

A modo de epílogo personal añadiría que ya en diciembre de 2018 con ocasión de las consultas previas al inicio de los trabajos para la elaboración de la propuesta de norma por parte del Departamento de Medio Ambiente, Planificación Territorial y Vivienda del Gobierno Vasco, (un periodo de tiempo para la consulta y participación ciudadana online), el asunto llamó la atención de algún medio digital de ámbito nacional súbitamente interesado por las cuestiones relativas a la habitabilidad. Nueve meses después y con el proyecto de decreto 
perfilado, remitido al parlamento y en vísperas de iniciar el periodo de consultas y aportaciones tras su presentación pública, se desató una inesperada polémica de sorprendente virulencia.

Nunca antes una norma técnica y de diseño había suscitado tanto interés y revuelo mediático. Radio, televisión, prensa escrita y redes sociales se inundaron de noticias, a cada cual más sesgada, incompleta o errónea, sobre ratios de superficie y relación entre estancias. Lo nunca visto.

Aunque muchos se escandalizaron y descubrieron por primera vez que nuestras viviendas son objeto de una exhaustiva regulación, desde todo punto de vista: de diseño, dimensional, constructivo, tecnológico etc., lo cierto es que esto es afortunadamente así desde hace décadas. No es menos cierto que en la actualidad la arquitectura se ve atravesada por distintos vectores que la condicionan: sostenibilidad medioambiental, eficiencia energética, participación ciudadana y ahora también perspectiva de género.

Unos dibujan campos más exactos, objetivos y medibles y otros son de carácter más difuso y tendentes a una mayor dosis de subjetividad interpretativa. Pero es que la arquitectura es siempre expresión de la sociedad que la genera. Y las normas que la regulan también lo son. La arquitectura ha sido históricamente un buen termómetro para dilucidar cuáles eran los valores subyacentes en las sociedades a la que pertenecía.

El arte de la regulación consiste en ser exhaustivo en las exigencias mínimas, las que han de garantizar los estándares exigibles y ser más abierto y flexible una vez garantizados estos. Alguien tan poco sospechoso de totalitarismo como Winston Churchill, dijo que primero hacemos los edificios y luego ellos nos hacen a nosotros. Y es que somos lo que habitamos. Por eso si aspiramos a unas viviendas adaptadas a las personas que habitan en ellas, y si tenemos en cuenta que estadísticamente las mujeres pasan mucho más tiempo en los hogares que los hombres, es ineludible pensar que las viviendas deben diseñarse considerando esa variable, que no es otra que su propio valor de uso. Algo tan sencillo como tener en cuenta a las personas usuarias, lo básico en cualquier escuela de arquitectura. Si aspiramos a una sociedad igualitaria, la inclusión de la perspectiva de género como variable del diseño resulta una obviedad. En realidad, lo realmente inaudito es que no se haya exigido hasta la fecha.
La sociedad cambia, y la arquitectura cambia con ella. La arquitectura de la vivienda y su normativa propia han ido incorporando a lo largo de los últimos dos siglos elementos de diseño emanados de los valores propios de los respectivos momentos históricos en que se encontraban: del higienismo filantrópico de finales del siglo XIX al ecologismo de principios del siglo XXI, pasando por el funcionalismo positivista del movimiento moderno que tanto marcó la gran mayoría de las viviendas del siglo $\mathrm{XX}$. No son corrientes estéticas, son corrientes de pensamiento cargadas de valores que impregnan y moldean la arquitectura.

\section{Bibliografía}

Belmonte, Rosa. (21/09/2019): "Cocretismo". Diario El Correo ed. Bizkaia. 88

DiReCción de Vivienda y ARQuitectura. Vice Consejería de Vivienda. Departamento de Medio Ambiente Planificación Territorial y Vivienda. Gobierno Vasco.

Proyecto de Decreto sobre condiciones de habitabilidad y normas de diseño de las viviendas y alojamientos dotacionales de la CAPV.

https://www.legegunea.euskadi.eus/document cion-relevancia-juridica/proyecto-de-decreto-que regula-las-condiciones-minimas-de-habitabilidady-las-normas-de-diseno-de-las-viviendas-y-aloja mientos-dotacionales-en-la-comunidad-autonomadel-pais-vasco/x59-contfich/es/

No existe versión editada.

DomingUeZ, J (19/09/2019): "EI Gobierno vasco quiere que los hombres entre en la cocina". Diario El Correo ed. Bizkaia. 1-16.

- (19/09/2019): "Pisos más versátiles flexibles eficientes y accesibles". Diario El Correo ed. Bizkaia. 16.

- (20/09/2019): “¿Cuantos deben caber en la cocina?" Diario El Correo ed. Bizkaia. 1.

- (19/09/2019): "Del fogón de la amama a la cocina de la igualdad". Diario El Correo ed. Bizkaia. 3.

Editorial (20/09/2019): "Hasta la cocina". Diario El Correo ed. Bizkaia. 30.

Editorial (23/09/2019): "Meterse hasta la cocina en la intimidad". Diario $A B C 4$.

FuENTES, Marian. (20/09/2019): "El Gobierno Vasco lleva a la cocina la lucha contra la brecha de género". Diario Expansión. 28.

GoLPE, Sandra. (20/09/2019): "El tamaño sí importa". Diario La Razón. 18.

GoRosPE, Pedro. (20/09/2019): "Cocinas con espacio suficiente para hombre y mujer". Diario El País. 28.

MAtEos, Adrián. (21/09/2019): "El gobierno vasco impondrá cocinas más grandes contra el machismo". Diario ABC. 40-41.

MonteYs, X (2014): La habitación. Urbanismo de 


\section{Estudios}

interiores. Barcelona, España. Editorial Gustavo Gili. NARVÁEZ, Pedro (20/09/2019): "Totalitarismo de género" Diario La Razón. 19.

REQUeREo, José Luis. (24/09/2019): "Viviendas ideológicas". Diario La Razón. 21.
RESA, Ángel. (20/09/2019): "De puertas para adentro". Diario El Correo ed. Álava. 4.

SEN, Cristina. (20/09/2019): "El Gobierno Vasco obliga a agrandar las cocinas para "combatir el machismo"'” Diario La Vanguardia. 31. 